\title{
Pediatric Anesthesia: A Problem-Based Learning Approach
}

\author{
Kirk Lalwani, Ira Todd Cohen, Ellen Y. Choi, Vidya T. Raman. Oxford University Press, \\ 2018, 656 pages. ISBN 9780190685157
}

\author{
Sophie N. Davie, MD, FRCPC (1)
}

Received: 16 February 2019/Accepted: 18 February 2019/Published online: 28 February 2019

(C) Canadian Anesthesiologists' Society 2019

One of the best ways to retain knowledge is to read around the types of cases with which one has been involved. It was with this theory in mind that problem-based learning (PBL) was adopted for medical education. In contrast to the conventional method of presenting the learner with facts and principles, PBL utilizes the technique of presenting an open-ended problem or situation and then guiding students through new concepts with which to address it. The editors of Pediatric Anesthesia: A Problem-Based Learning Approach effectively put PBL into action to discuss a wide array of topics on pediatric anesthesia.

The book is divided into 11 sections by organ systems (cardiovascular; thoracic; head, neck, and respiratory; neuromuscular and spine; gastrointestinal; renal and urinary; endocrine and metabolic; hematologic) as well as dedicated sections for prematurity and neonatal surgery, pediatric pain, and a final chapter on miscellaneous diseases, trauma, burns, autistic patients, adolescents, and ethics. Each section contains several chapters, with each chapter focusing on a specific clinically relevant pediatric anesthesia topic. The chapters are presented in PBL format, starting with a case, asking questions about it, and then discussing it. This format provides a complete, yet succinct, review of the topic.

As an example, the section on the cardiovascular system offers trainees a strong introduction to common congenital cardiac lesions. There are clear descriptions of the anatomical defects, along with an explanation of the pathophysiologic implications. Clinical manifestations, natural course of the disease, and appropriate treatments are reviewed. There is also a brief overview of the surgical management and anesthetic considerations for the cardiac

\footnotetext{
S. N. Davie, MD, FRCPC ( $\square)$

Department of Anesthesiology and Pain Medicine, University of Ottawa, Ottawa, ON, Canada

e-mail: umdavie@myumanitoba.ca
}

surgery. Perhaps more relevant to the trainee and general pediatric anesthesiologist is mention of the anesthetic considerations for the patient with a congenital cardiac condition presenting for non-cardiac surgery. For example, the chapter on ventricular septal defects describes the classic situation of a patient with Down syndrome and an unrepaired such defect scheduled for a general surgical procedure.

This book can serve as a useful resource for both learners and teachers of pediatric anesthesia. The trainee would do well to read this book cover to cover to gain an understanding of most topics relevant to the pediatric anesthesiologist. The PBL format actively engages the student with its easy-to-read text. Nevertheless, the reader should be warned that there are chapters where the "Key Questions" about a case are either incompletely addressed or not answered at all in the "Discussion" section - which could prove frustrating, especially for trainees.

An attribute of Pediatric Anesthesia: A Problem-Based Learning Approach is the accompanying "Questions and Answers" section that is provided online. Generally, five to ten multiple-choice questions are provided per chapter. Unfortunately, like the chapters themselves, there are some inconsistencies in this section. For some chapters, the questions are answered along with an in-depth explanation and references, which helps consolidate the learning material and is useful for self-evaluation. Other chapters' questions, however, have only an answer key to follow, with no explanations or references, making the book a less valuable resource.

For educators, this book offers a template to follow when leading discussions. The average chapter takes 30-60 min to read, making it a reasonable resource for a trainee to review prior to a clinical case. In the Preface, the editors mention that teachers could provide students with the "Stem Case and Key Questions" section and withhold the "Discussion" section for the teaching session. However, 
instructors should be aware of the organizational inconsistencies among the chapters. Although some chapters are well suited for this method of teaching, others have the answers included in the "Stem Case and Key Questions" section, which would necessitate a different teaching strategy.

In conclusion, Pediatric Anesthesia: A Problem-Based Learning Approach is a useful book for students interested in pediatric anesthesia and teachers in this field. All the topics covered are clinically relevant, and most are both thorough and concise. Trainees may find that some topics will require further study to obtain a complete review. Learners are encouraged to discuss the main learning points gained from the chapter with an educator to determine if further study is required. Because of the inconsistencies in the book, it is recommended that educators review the chapter of interest prior to a teaching session to determine the best way to utilize this text and to decide whether supplemental resources are required. Overall, however, this book is a good resource for most topics in pediatric anesthesia and will certainly promote discussion among trainees and educators.

Conflicts of interest None declared.

Editorial responsibility This submission was handled by Dr. Hilary P. Grocott, Editor-in-Chief, Canadian Journal of Anesthesia.

Publisher's Note Springer Nature remains neutral with regard to jurisdictional claims in published maps and institutional affiliations. 